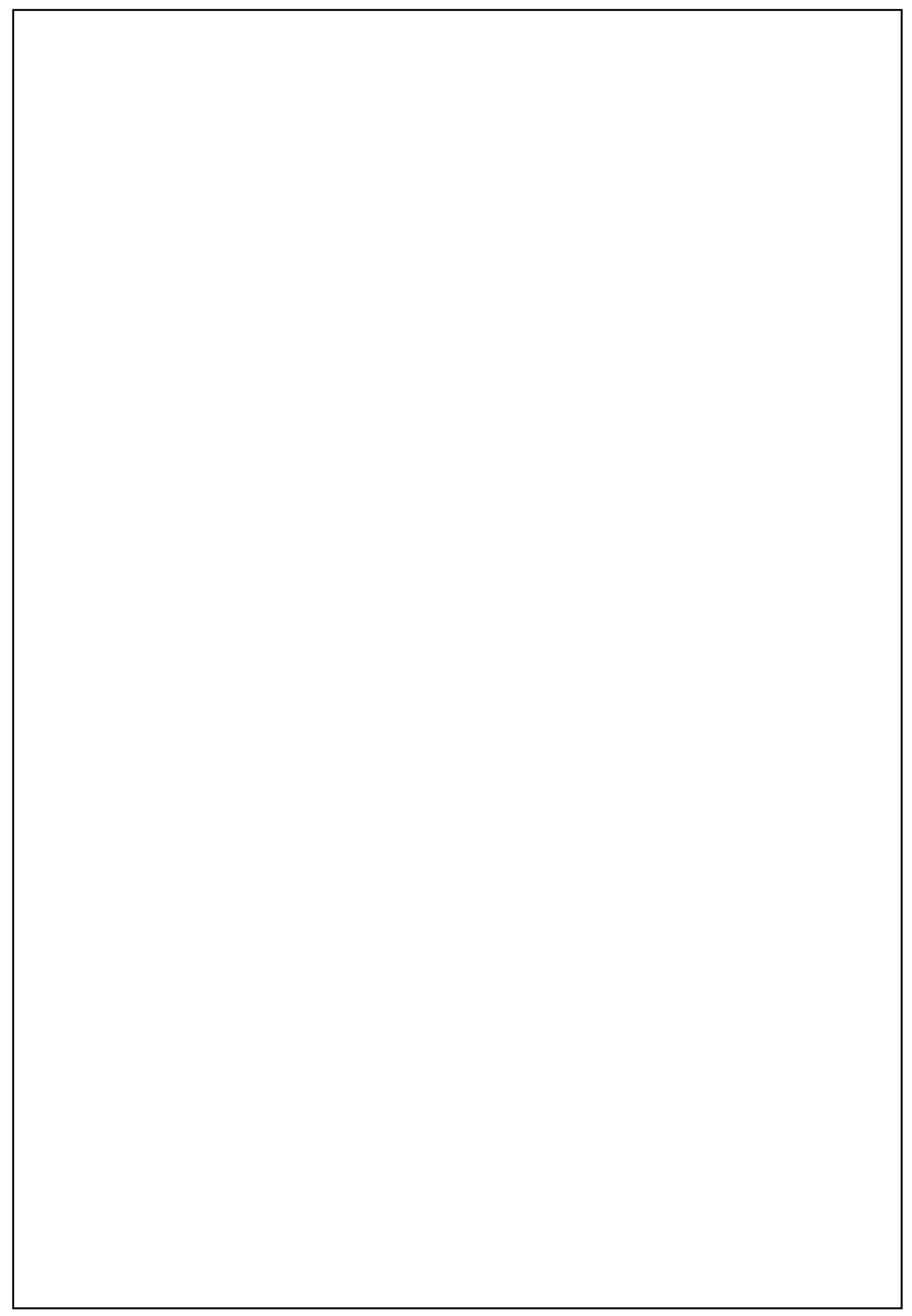




\title{
Status of Women in Pakistan: A Critical Analysis
}

\author{
Dr. Samina Isran ${ }^{1}$ \\ Dr. Manzoor Ali Isran ${ }^{2}$
}

\begin{abstract}
The status of women in Pakistan is worsening day by day and their living standard is also decreasing abysmally. Women in Pakistan do not only suffer from domestic inequalities in terms of the distribution of resources but their access to outside resources like education and employment is minimal and support from government or non-governmental organizations is nominal. Patriarchal structures embodied in kinship, religion, division of labour, violence and class hierarchy have further reinforced subordination of women and their dependence on men. The inability of state to fulfil basic needs of people has increased the number of poor women in the country. This study attempts to present an analysis on the plight of women and widening gender inequalities being reinforced by patriarchal set up and norms in Pakistani society. The analysis is done in the light of two main analytical frameworks: Women in Development (WID) and Gender and Development (GAD). The methodology applied for the study is qualitative. The study concludes that until gender inequalities are removed, women would continue to suffer from subjugation in Pakistan; therefore, state should adopt more gender sensitive human development policies and ensure women's representation and participation in all the crucial domains.
\end{abstract}

Keywords: Gender and development (GAD), patriarchal structures, women in development (WID), women in Pakistan

\section{Introduction}

\subsection{Background of the Study}

Women in Pakistan are faced with a plethora of socio-economic, cultural and religious obstacles that have deplorably marginalized their status in the society. They are not entitled to their due space and their choices about productive and reproductive labour are curtailed. Gender inequalities between men and women have reached to the alarming level where women have lost their identity; their concerns are unheard and unrepresented in the national accounts and policies. The labour they do in the household is unaccounted for and their labour in the market is undervalued. Their contribution in the productive and reproductive activities is unrecognized and they are considered as what Young (1997) describes as "workhorses". Diane Elson (1995) attributes women's predicament to gender-blind development policies, which instead of promoting human resources, are depleting them upon which the reproductive and productive processes are dependent. He also describes that these policies are very much biased against women. The institutionalization of such biases has created structures that have deprived women of their entitlement to the resources considered necessary for their emancipation process from the clutches of exploitative patriarchal system, rendering women to low status in the society.

\footnotetext{
${ }_{1}^{1}$ Dr. Samina Isran is Assistant Professor, Department of Economics, Shah Abdul Latif University, Khairpur, saminaisran@hotmail.com

${ }^{2}$ Dr. Manzoor Ali Isran, Assistant Professor, Faculty of Social Sciences, SZABIST, Karachi, isran@ szabist.edu.pk

\begin{tabular}{llll|l}
\hline JISR - MSSE & Volume 10 & Number 2 & July 2012 & 85
\end{tabular}
}


In fact, Pakistani society, as a whole, is built around the family and household set up. Kinship and marriage are the basic institutions of the social structure. The predominant force in the matrix of the social organisation of society is patriarchy, and this is mainly used to suppress women at every level (Alavi 1991). The patriarchal social culture and norms are said to be responsible for hindering women's access to vital economic resources like credit, education, gainful employment and other income generating activities which are considered crucial for their stronger position and bargaining power (Mumtaz 2007). The cycle of inequalities and discrimination, which Pakistani women are faced with, starts from the household and ends at the level of state policies that are predominantly based on the patriarchal ideology. As a result of these inequalities and discrimination, many women have been exposed to the curse of subordination and marginalisation in both household and society. Such plight of women has been approached differently by liberalist and socialist feminists.

Therefore, the two approaches, Women in Development (WID) and Gender and development (GAD), shall be used as analytical tools to analyse women's low status and their subordination and marginalization in the society in the subsequent subsections. These approaches, too, focus on the realisation of women's practical and strategic gender needs. Practical gender needs refer to women's access to food, safe water, shelter, steady source of income, access to education, training, credit and so on so forth and Gender strategic needs refer to emancipation of women. The strategic needs particularly come into focus when the women's position in the social matrix is questioned. Strategic needs question the inequality between men and women. These inequalities are embedded in culture, class and are said to be value specific (Young 1997). These inequalities, for one reason or the other, have widened as the development processes under the so-called modernisation have progressed. The events leading to such gender inequalities question the fundamental assumption about the nature and causes of inequality. Hence, the focus has shifted from culture, class race to gender. The attempts are being made by feminist groups to get women united on the gender issues arising from their subordination as weaker gender. Obviously reason behind such attempts is to find ways of transforming the situation. The issues most commonly identified are: male control of women's labour, women's access to social and economic resources and political power, and as a result of uneven distribution of such resources between gender, male violence and control of women's sexuality. The paper, further aims to explore Pakistani women's actual position in terms of their work and provisions of fundamental rights such as property, assets, credit, and employment and also their low status in the household and society.

In South Asian societies, particularly Pakistan, a central and systematic form of control is patriarchy, which, is the main cause of women's suppression. Therefore, the analysis of patriarchy and its implications on the lives of women is the main focus of the analysis of this study. With regard to women's position and status in Pakistani society, women still find themselves struggling to be treated as equals in social, political and economic spheres. Despite the acknowledgement of women's productive potential and their different economic roles, Pakistani women still face seclusion and exclusion due to socio-cultural norms based on patriarchy which deny them access to the benefits of development.

\subsection{Significance of the Study}

The study intends to highlight factors and issues which influence and affect women's role and position. An examination of the activities and agendas of women's rights groups in Pakistan reveals that their role is changing gender relations. To make the socio-economic system more inclusive and allow it to integrate the majority of rural women, efforts must be made towards increasing women's economic self-reliance and raising awareness of micro level issues, directly affecting them, which are directly related to macro level structures and processes. According

\begin{tabular}{l|llll}
86 & July 2012 & Volume 10 & Number 2 & JISR-MSSE
\end{tabular} 
to socialist feminists greater acquisition of economic power together with education, training, knowledge, information and increased communication amongst women can help challenging patriarchal norms and cultures and in enhancing their bargaining power within the household (Kumari 1986).This will also create an environment conducive for women's empowerment at grassroots level. The study will help development theorists and practitioners and students, alike, to understand the reasons of underdevelopment of Pakistani women and their exclusion from the development process.

\section{Literature Review}

\subsection{Obstacles for women}

In Pakistani society, women face different predicaments which have not only lowered their status in the society but reduced their productive roles in the socio-economic change. In the following sections, different obstacles are discussed in detail.

\subsubsection{Kinship System}

The most important obstacle in patriarchal set up is family structure and Biraderi system. Patriarchal family structure is perhaps the most important component that subjugate the power of women within the households (Niaz 2003). The custom of patrilocal marriage (a form of marriage in which the wife goes to live with husband's family), takes a newly-married woman from her family of birth and places her in her husband's household. Preference for Biraderi, and village exogamy attenuates a woman's ties with her family of birth and reduces the possibility that her parents will intervene on her behalf after her marriage. Exogamy and physical separation also make it less likely that a woman will claim her share of inheritance and more likely that her brothers will seize control of her share of inherited land regardless of her wishes. Arranged marriage as is the case of many rural parts of the country, and differences of age between husband and wife places a woman in a subordinate position relative to her husband at the outset of marriage. Furthermore, evidences suggest that when a woman receives a substantial dowry upon marriage, this is taken away by the husband or in-laws, ultimately depriving her of independent security.

\subsubsection{Violence against Women}

Violence against women is another obstacle for women in Pakistan (Shaikh 2003) and (Niaz 2003) and patriarchy is at the core of that violence, generating and promoting more gender disparity which is crudely displayed by the virtual existence of violence against many rural and urban women, whether in their households or outside. The patriarchal family structure isolates most of the women within their households, and in most cases wife beating is considered as a private issue in which any outside intervention is never welcomed (Niaz 2003) and (Ali \& Gavino 2008). There is no law against domestic violence in virtually half of the countries in South Asia (UNDP 2010). But most recently an encouraging development has taken place in Pakistan. Recently in southern province of Pakistan, Sindh's provincial assembly unanimously passed the domestic violence bill making its violation punishable by fine and/or imprisonment (Dawn, July 27, 2013). This decision has been hailed by NGOs and civil society as major breakthrough against domestic violence faced by women. But issue here in Pakistan is the implementation of such laws which does not take place automatically due to institutional breakdown and male dominance. There is a greater need for creating mechanism to implement laws. In this regard, separate judicial courts being headed by women judges be established for the trial of such cases on speedy basis in order to stop domestic violence against women.

\begin{tabular}{llll|l}
\hline JISR - MSSE & Volume 10 & Number 2 & July 2012 & 87
\end{tabular}


However, the violence against women is rampant in Pakistani society. Usually, the incidence of wife beating and domestic abuse is less in the households with high education and economic status but psychological suppression and oppression may continue (Panda \& Agarwal 2005). In addition to this, crimes such as high demands for dowry, murder by husbands or in-laws (allegedly attributed to kerosene stoves for accidentally bursting into fire), fall in the domestic abuse category. Most of the victims are women belonging to the poor families. The sale of girls in Khyber Pakhtunkhwa, forced marriages and Honour killing in rural Sindh, gang rapes in rural and small towns across the country are daily occurrences (Mumtaz 2007).

Honour killing is a different type of familial violence against women in Pakistan. The practice of karo-kari can be seen in many parts of the country. Official figures reveal that more than 4000 thousand people, including 2800 women have become the victims during 1998 to 2004 in honour killing cases. Moreover, figures also show that in 1997 there were 86 karo-kari killings in Larkana, Sindh province, alone, with 53 of the victims being women (Felix 2007). According to HRCP report (2011), nearly 675 Pakistani women murdered in the name of honour (Hali 2013). The World Economic Forum (2012) ranked Pakistan as the worst in its Global Gender Gap Report.

\subsubsection{Political Participation}

Another important obstacle for women in our society is to deprive them of their legal and political rights. Hence, they are political and legally disempowered and their political participation is curtailed systematically. Generally, political participation can be defined as access to positions of political power and the ability to influence the decision-making process at the levels of community and formal institutions. Women are discriminated across the world in their participation in political decision-making, especially in South Asia and Sub-Saharan Africa (UNDP 2011). But in the case of Pakistan, lack of women's participation in formal governing bodies has to be related to the general socio-economic conditions and also to their weaker position and related bargaining strength within and outside the household. Factors constraining their participation are also created by the political game that has placed powers firmly in the hands of the bureaucratic and land-owning elites, where the actors and protagonists are men. In part because of the male domination of political institutions, and in part because formal judicial institutions and administration are weak, legal protection for women (under either civil or Islamic laws), is nominal. If a woman who is litigant in a land dispute, for example, is not closely related with and supported by a man, she is likely to lose the case regardless of the merit of her case.

No doubt, some positive steps were taken by the previous regime of Pakistan People's Party (PPP) for the provision of legal rights of women. In January 2010, the president signed the 'Protection against the Harassment of Women at Workplace Bill 2009, which was passed by the parliament. Two additional bills were also signed into law by the President in 2012, against the traditional practices of vani, watta-satta, swara and marriage to holy Quran, which used women as tradable commodities for the settlement of disputes, in addition to life imprisonment for acid throwing (Pakistan Economic Survey, 2012-2013). There is still an urgent need for more such forward looking laws and amendments and their fair implementation for improving the political and legal status of women in Pakistan.

\begin{tabular}{l|llll}
\hline 88 & July 2012 & Volume 10 & Number 2 & JISR-MSSE
\end{tabular}




\subsubsection{Religion}

Patriarchy gains strength from religion in a country like Pakistan (Mumtaz 2007). Islam has a greater influence on the expectations and behaviour of women in Pakistan. Islam is explicit about the sexual division of labour and responsibility and, in effect sanctifies male dominance. According to Islam, men and women have their own spheres of activity, a scheme of a functional division in accord with their respective natural dispositions and inherent physical and physiological qualities and characteristics. Two more aspects of Islam as interpreted in Pakistan, have direct impact upon women as instruments of patriarchal control: the laws of inheritance and the manifestation of purdah, the female seclusion.

However, Muslim inheritance laws allow a daughter one-half the share received by a son. In practice, a woman frequently receives less than her rightful share under the law. Moreover, if a woman inherits land, her husband cultivates it (when accessible), as if it were his own. A number of observers have also noted a tendency for women to relinquish their share of inheritance to their brothers as a way of gaining favour and generating good will (Jeffery 1979). Purdah is a system of secluding women and enforcing a high standard of female modesty, and its manifestations in Pakistan include severe restrictions on women's movements outside their households (Mumtaz 2007) and standards of dress that hide their face and body.

\subsubsection{Division of Labour}

Rigid division of labour is also a patriarchy-related obstacle in Pakistani society. Patriarchal structures that force many women into relative seclusion in the household, also deny them access to most forms of market work (Sathar\& Kazi, 2000, Mumtaz 2007). A recent UNDP Report (2010) indicates that in South Asian countries (including India and Pakistan), lesser than 35 percent women are engaged in paid work. A study by Amin (2012) explored that women's share in paid work had actually shrunk from 33 percent in year 2000 to 21 percent in 2011 (Saeed 2013).

Ironically, due to the lack of access to such economic resources many women have lower bargaining power for their proper share within the household. In Pakistan, the division of labour among household members has evolved whereby women specialise in work inside or near the household, (food processing and preparation, household maintenance), and men specialise in working outside the home (trading, and other forms of market work and transactions). This division itself engenders a powerful element of patriarchal control over women, reinforcing women's dependence on men denying them direct access to income-generating opportunities. The gender division of labour applies in large part to all women, regardless of economic status or household structure. As a consequence, women are totally excluded from most wage employment, and the cost, in terms of abuse and loss of status, of engaging in other types of work that require movement outside the household (e.g. petty trading), are very high indeed.

To a greater extent the age, sex, and class hierarchies also influence patriarchal control in Pakistan setting. For example, among women, solidarity and potential resistance are undermined by an age hierarchy that accords older women with patriarchal interests, and by class differences between women. In general, newly married women are dominated by their mother-in-laws. This age stratification among women allies older women with patriarchal interests and also gives younger women something to look forward to with advancing age (Ali \& Gavino 2008). Similarly among poor men, for whom the material benefits of patriarchy are less than for the relatively rich, and whose well-being might improve if their wives could engage in better employment, potential resistance is blunted by their position of dependence in the class hierarchy. Whereas,

\begin{tabular}{llll|l}
\hline JISR - MSSE & Volume 10 & Number 2 & July 2012 & 89
\end{tabular}


it would be unwise to categorise all Pakistani women as a homogenous group, as there is a greater regional, ethnic and geographical variations in the society (Ibraz \& Fatima 1993). Also, the status and livelihood strategies of women cannot be regarded as similar in all sections. Although all of them are involved in common roles of reproduction, child bearing and household maintenance, the degree and mode of involvement in unpaid and income earning activities, and degree of changes in activities and position, vary between different classes and households.

\subsubsection{Poverty and Women}

Poverty is considered as a consequence of all the above-mentioned obstacles generated by patriarchy, which badly curtails women's choices and their right of independent decision-making regarding their education, career and access to other vital resources. In this section, a picture of the extent of gender poverty in Pakistan, as a statistical measurement, will be portrayed and some of the problems involved in defining poverty levels will be discussed. This leads to an attempt to identify the social characteristics of the poor and less privileged groups (in this case women), in Pakistan society, and to an analysis of some of the main causes of gender poverty. Over and above obvious starvation and destitution, the definition of a poverty level that is sociological significant remains problematical. In the case of Pakistan, attempts to measure poverty have mostly been based on nutritional standards and on expenditure and income levels. Both per capita expenses and household income are used as barometers to measure standard of living but it includes other important sectors of welfare like life expectancy, health, literacy and access to public services.

According to the World Bank, poverty is "the inability to attain a minimal standard of living", which certainly hinges on a specific income value (World Bank 1989). A recent report issued by UNDP (2013) depicts that the proportion of the population living in multidimensional poverty is 49 per cent and the intensity of deprivation is 53 per cent in Pakistan. The report further documents that although a larger proportion of the population (head counts) lives in multidimensional poverty in Bangladesh than in Pakistan, the intensity of deprivation is higher in Pakistan.

A study by Saeed (2013) reveals that the World Bank estimates that 1.29 billion world's population live in absolute poverty and about 70 per cent of them are women. The level of poverty is more severe in the rural areas where this proportion becomes one-third (World Bank 2002), to onehalf and women disproportionately share the burden of poverty (Abdullah 2012), which has a two-fold impact. On the one hand, the women's workload for family survival increases and on the other, their share in food and nutrition intake decreases. In fact, the persistence of gender poverty in Pakistan is rooted in socio-cultural inequalities accentuated by patriarchy. The Planning commission of Pakistan does not reveal the exact data on female poverty. The World Bank (1999) in its 'Country Gender Profile of Pakistan' laments that the status of women in Pakistan is among the lowest in the world. Another report deplores the fact that those women and girls in poor households bear a disproportionately high burden of the share of poverty (Abdullah 2012). It narrates that their greater deprivation is due to low social status, lower endowment of land and productive assets compared to men, and their very limited access to economic options and social services (World Bank 2002).

The reason behind this is that poor women as a target group belongs to a socio-economic class that does not have much power or influence to improve their position under the current political and male-dominated administrative arrangements in Pakistan. Undoubtedly, women are vital contributors to the economic survival of poor households, and the reliance on women's earning increases with the extent of poverty.

\begin{tabular}{l|llll}
90 & July 2012 & Volume 10 & Number 2 & JISR-MSSE
\end{tabular}


The second reason is that majority of the poor population lives in rural areas (World Bank 2002) and most of the poor women's labour is concentrated in the agricultural sector, which is low paid, and more importantly it is seasonal and limited to selected regions. Despite high participation rates, women in rural areas cannot find adequate work on a regular basis. According to some estimates, dependence on agricultural wage work as the main source of employment is higher for rural women than rural men. Such higher rates of women participation in the agricultural wage labour is related to the increasing mechanisation of male-related tasks, the introduction of tractors has replaced male labour whereas mechanisation has not yet been extended to the predominantly female tasks such as weeding, transplanting, harvesting, and storage and preservation. Many other rural women have been drawn into informal and non-agricultural activities to cope poverty (Mumtaz 2007).

The situation in urban areas is not different where poor women are faced with the same sort of situation, due to lack of education and skills, women have less options in terms of good salaried jobs and they take low-paying menial jobs at the lowest rungs of the informal sector as domestic servants, or as home-based workers who are either self-employed or working under the subcontracting system. Such informal set up has made women's labour cheap and stripped women of their entitlement to their rights such as maternity leave, health, child care and other benefits.

\subsubsection{Women-headed Households}

Due to such large-scale social and economic injustices, the women-headed households in Pakistan have suffered a great deal. Women-headed households are defined as those households which have little apparent reliance on a male bread-winner, adult men being most usually absent from any financial, spatial or emotional proximity to the unit of women and their children. Such households are now estimated by the United Nations to comprise about one-third of all households of the world and a disproportionate number of poor ones. Female household heads is a category considered to be increasing in number (Saeed 2013), and requires policy attention (Khan \& Khan 2007).

According to national socio-economic surveys, female-headed households are less than eight per cent of all households in Pakistan. But this is said to be an underestimate as, the gender bias could be embedded in such reports. It should be noted that in the patriarchal society of Pakistan, it is almost inconceivable that in the presence of male elders, a woman becomes a head of the household, except in the case where the husband is disabled or too old. Another instance is when her husband has left home for a job or is otherwise absent from home. In the third instance, she becomes head of the household when she is widowed, divorced, or separated. In any case, a Pakistani woman is accustomed to her subordinate position in the household, and even when she is entrusted with authority, she hardly exercises her will. This situation is particularly prevalent in rural areas, where cultural values are strong as compared to urban areas. Findings from Pakistani data show that households headed by women are found in the poorest strata of society. Ray (2000) narrated that female household heads are more vulnerable to poverty.

Apparently, this low status of women-headed households is the result of economic factors. In economic terms the explanation of poverty in female-headed households lies simply in the lower earning capacity of these female heads. The main source of income in female-headed households is the head's earning which, on average, is comprised of the total family income. Thus, the occupation and income level of the female head of household determines the level of earning of the household. But the main factor responsible for the situation faced by the women-headed household is that the women have little or no education and skills related to the household sphere.

\begin{tabular}{llll|l}
\hline JISR - MSSE & Volume 10 & Number 2 & July 2012 & 91
\end{tabular}


Lack of education and training limits their employment opportunities to low paying, menial jobs. As a result, female heads are over-crowded in the lowest occupation group. They face hardship in maintaining their families because they have limited access to market economy, when they work their wages are far lower (Khan \& Khan 2007). Despite all these hardships and difficulties, women head of the households are more concerned about the welfare of both male and female members of their families and give them equal rights.

\section{Theoretical Debate}

There are volumes of theoretical literature available that discuss the issues related to asymmetrical position of women in the patriarchal system and suggest ways and means to free them from socio-economic, cultural and religious traps within patriarchal system, incapacitating women to play vital role in the development of society. These debates range from Women in Development (WID) to Gender and Development (GAD). Both approaches attempt to set women free from the patriarchal yoke. WID finds solution within existing capitalist social and economic order but GAD is more radical in its tone and tenor and stands for total alteration in the patriarchal relationship within household on the basis of equality. Social restrictions are mostly seen in the society where patriarchal system is strong and religious beliefs about male and female segregation are deep rooted. Such practices are common in most of the Islamic countries like Pakistan and Iran where cultural and social attitudes are determined by such beliefs. As a result, social structures are very much rigid and people are less willing to accept social change easily.

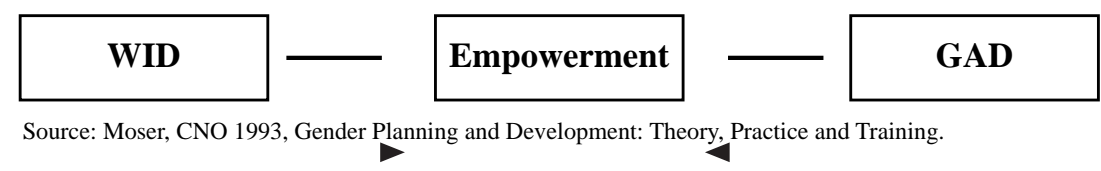

Figuer 1: Approaches to Empowerment.

\subsection{Women in Development Approach}

The fundamental premise of WID lies squarely with the framework of liberal feminist's theory, which requires rational individual to free oneself from social encumbrance (children, family and community (Young 1997). Liberal feminists cite gender-based divisions of labour as the main cause of women's unequal status and social position and finally exclusion from development processes. For the integration of women into mainstream of economic, political and social life, they suggest changes in law, institutions and attitudes and acquisition of high level of education and training. However, despite several conceptual and methodological pitfalls, WID is the official policy of international aid agencies.

The problem with WID is that it has always depicted the development, as linear process by taking simplistic view that the women will be well integrated in the modernization process if they are allowed access to education, technology and labor market. This view, too, was adopted by Boserup (1970) in her first ever study discovering the marginalisation of women from the modernization process by the capitalist development models. Boserup attributed such exclusion of women to the colonial and post-colonial development discourses. In her critique on the modernization theory, she argued that colonial and post-colonial discourses failed to integrate women into development and modernization models and have not helped women to benefits

\begin{tabular}{l|llll}
92 & July 2012 & Volume 10 & Number 2 & JISR-MSSE
\end{tabular}


from the generous development process. For the greater and active role of women in development, she, therefore, underlined the need for more equal and easy access to training, education, and technology. She noted if the societies were to function efficiently, there would be need for better education, training, not only of men but also of women (Boserup 1970).

\subsubsection{Equity Approach}

Based on these theoretical formulation of Boserup (1970) and concomitant rise of movement in the US by women groups for the equality of women with men in all walks of social economic and political life, WID changed its approach from welfare to that of equity. The adoption of the equity approach as official policy of the international aid agencies and backing of industrialised countries was celebrated by the liberal feminists. It was considered as radical step towards the emancipation of women. Under the equity approach, the triple role of women was recognised. To sum up, the equity approach challenged the subordination of women and envisaged the greater political and social autonomy of women so that they can play active role in the development process as contributor (Moser 1993). This implies that women are active agents of development, and they through both reproductive and productive roles can make critical contribution to economic growth and thereby social and cultural change. So, economic growth was seen as an instrument of narrowing gap between men and women. It was more embedded into developmental approach and underlined the need for women's access to education, training and market place as a first step towards the greater goal of women's autonomy from patriarchal controls. The equity approach was criticized on the ground that it was top-down, giving upper hand to the bureaucratically managed development agencies in the execution and implementation by disregarding the concerns of poor, especially of women at the bottom. Methodologically, it did not have a single unified indicator to measure the social status or progress of women out of baseline information about women's economic, social political status (Moser 1993, p. 65).

\subsubsection{Anti-poverty Approach}

In the presence of antagonistic atmosphere, the debate about the identification and application of appropriate strategy ultimately led to the axing of equity approach. As such, it was replaced by the anti-poverty approach. According to Moser (1993), anti-poverty approach was the toned down version of the equity approach. It was designed to raise the productivity of women. It viewed women's poverty as the problem of underdevelopment, not of subordination. Hence, it shifted its focus from reducing inequality between men and women to reducing income inequality.

Apparently, the introduction of the anti-poverty approach recognised the fact that modernisation process, with accelerated growth strategies based on maximising GNP, had failed either to redistribute income or to solve the problem of Third world poverty and unemployment, making the rich richer and poor poorer. Under the anti-poverty programmes this time the strategy was changed and the "working poor" were recognised. The institutions like World Bank shifted its focus from economic growth to a broader concern with the eradication of absolute poverty and promotion of redistribution with the growth. Integral to this was the "basic need strategy", of which main concern was food, clothing, shelter and fuel. It also addressed the issue of social needs, which included education, human rights and participation in the social life through employment and political involvement.

Like its predecessor, equity approach, the anti- approach was also top-down, gender-neutral and narrow in its focus. It was more gender-specific and attempted to encourage women in the traditional occupation in which women were already concentrated such as sewing and plantation.

\begin{tabular}{llll|l}
\hline JISR - MSSE & Volume 10 & Number 2 & July 2012 & 93
\end{tabular}


Furthermore, in theory, basic need strategy assumed participatory approach but in practice antipoverty projects rarely included participatory planning procedure. According to Moser (1993), antipoverty projects did not facilitate women's access to available raw material, markets and small-scale productive activities. Moser further argues that gender role which women frequently experience in the daily life were conspicuously ignored, which included the separation of reproductive from productive work as well as those associated with balancing productive work alongside domestic and child care responsibilities. Also, anti-poverty projects accorded low priority to women's micro-enterprise tendencies by reducing their entitlement to credit facilities. It amply demonstrates that the anti-poverty approach miserably failed to address the critical issues of women such as redistribution of power, introduction of new and modern programmes, women's entitlement to credit and balance between women's reproductive and productive work.

\subsubsection{Efficiency Approach}

Efficiency was the third approach introduced as policy instrument of WID to handle the integration problem of women. The efficiency approach, introduced under SAP, is based on the concept of the elasticity of women's time. Women are seen primarily in terms of their capacity to compensate for declining social services by extending their working hours and days. It is too much over stretching for women to cope with the three tasks of working, child bearing and household maintenance. Several studies show that the development projects launched under the SAP have marginalised women from the development and have left terrible effects on the women.

According to the study of Stewart (1992), investigating the roots cause of the SAP models on women, observes that the sufferings of women have emanated from the inflationary policies mostly perused under the SAP. These policies put cutbacks on the demand side under which the expenditure on the social services like health and education is curtailed, subsidies on the items like food and essential utilities are withdrawn and the role of state, as the main employer, is drastically trimmed. To sum up, in the light of all these studies, it could be established that the SAP policies are designed to seek the expansion of capitalism by using women as 'human buffer'. Ironically these models are very much biased against women.

The above discussion on the WID approaches amply demonstrates that the neoliberal development models have totally failed to address women's vital concerns. The major problem with the WID is that it has conceived women's problems in terms of sex-biological difference from men rather than in terms of gender, which focuses on the social relation between men and women, in which women have been systematically subordinated. WID, despite change in its focus from welfare, equity, anti-poverty to efficiency, is based on the underlying rational that development processes will proceed much better if women are fully incorporated. But the facts speak contrary to these tall claims. The reason is that WID trajectories of the development have treated women in isolation, and promoting measures such as access to credit and employment as the means by which women can be better integrated in to the development have failed.

\subsection{Gender and Development (GAD)}

Being confronted with this kind of situation, which many of the developmentalists describe as 'impasse' emanating from men's ego to accept the right of equity to women has led to the radical debates by the socialist feminists. They believe that liberal WID regime instead of empowering women have disempowered them. Chowdhry (1995) in her criticism of WID, argues that liberal discourses have given Third World women Zenana (feminist) representation, according to which they are dubbed as "mindless members of harem, preoccupied with petty domestic rivalries rather than with artistic and political affairs of their times". They are inferior to Western women

\begin{tabular}{l|llll}
94 & July 2012 & Volume 10 & Number 2 & JISR-MSSE
\end{tabular}


who do not wear a veil and who have nothing in common with this tradition bound image.

Mohanty (1997) in her critique attributes the sufferings of the Third World women to the patriarchal system being underpinned by the modernisation. Jayawardena (1986) picks up similar strand of thought. While referring to the liberal economic development models, she says that there is a tacit assumption that the status of women can be improved by making them, even in the restricted sense, economically independent. Besides, the income generating activities on self-employment basis, there is also an emphasis on drawing women in to the labour force. But what is missing from these models is that there is no questioning of the patriarchal structures of society, which is at the heart of women's subordination. Therefore, the relative independence of the women does not contribute to her emancipation. In fact, she becomes doubly oppressed; she has to bear the dual burden of paid wage work and unpaid domestic labour. The development approach may, therefore, result into binding women more firmly to her subordinating status. Women are, in fact, being integrated into a process of development that still continues to be exploitative and oppressive as it is male-dominated and male-oriented (Jayawardena 1986).

The argument of Kumari (1986) implies that the existence of the patriarchal system is the main source of women's all troubles, ranging from subordination in the household to marginalisation in the market. According to this line of thought, the women's emancipation from the exploitation and oppression could not be realised unless the existing patriarchal system operates in most of the societies of the developing countries is over thrown by grassroots women's organisation through political mobilisation. Hence, focus of socialist feminists is on the reconstruction of gender relationship as pre-requisite for free and fairs entry of women in the arena of development. This reconstruction involves gendered division of labour where the burden of the work is equally distributed between men and women. Let us have a glance at the Gender and development Model, which stipulates the socialist feminists' strategy about the emancipation of women.

The emergence of the GAD is attributed to the failure of the liberal WID regime to address the empowerment of women in substantial way. The main weakness of the WID approach, according to $\mathrm{GAD}$, is that it has treated women in isolation, ignoring the real problem of women's subordinated status to men. It emphasises a focus on gender relations while designing development planning. GAD, unlike WID, mainly focuses on the economic as the main determinant of women's role in society while taking holistic view of men and women's role in the society. Basically, GAD approach has been built upon the fact that men and women play different roles in society, with their gender differences shaped by ideological, historical, religious, ethnic, economic and cultural conditions. Therefore, there is no single determinant to be held responsible for women's subordination. There are similarities and dissimilarities in women's roles in terms of class, race and ethnicity and so on. And as such differences in social categories, therefore, differentiate the experience of inequality and subordination within different societies.

So, this holistic view of GAD about men and women's roles make it distinct from WID. Coming in to existence in $1980 \mathrm{~s}$, the period in which the sufferings of women were investigated by different studies due to the SAP projects, the feminists from the South severely criticised the liberal development models, which instead of trickle down the benefits of the development had trickled up. The advocates of GAD approach maintain that while WID lays great emphasis on providing women with opportunities to participate in male dominated social, economic and political structures. On the contrary, GAD seeks women to play role of an agent of change, rather being merely recipients of development assistance and stress the need for women to organise themselves for effective role.

\begin{tabular}{llll|l}
\hline JISR - MSSE & Volume 10 & Number 2 & July 2012 & 95
\end{tabular}


However, GAD is less popular with the international aid agencies. It envisages great social transformation in the socio-economic structure of the society so that woman can be placed in the mainstream of development activity. It is described as more of feminists concern. Yet many of the feminists group consider GAD as the panacea that can put an end to women's sufferings and deprivations. It may sound true but the problem is that GAD cannot be applied in all societies, especially those that have rigid social structures and are averse to abrupt social change. For example, the society, like Pakistan, is marked by the rigid social structures, which are less responsive to quick social and cultural changes. So, to talk with women straightaway about the change of patriarchal system may not be acceptable to them, as it is bound to affect women's vital interests. Therefore, the application of GAD is best suited in the societies like Eastern European countries and Latin America where women's potential is sufficiently strong to bring and sustain the social change at large scale. In contrast to GAD, the WID approach is considered more hierarchical, genders blind and full with male biases. It offers just cosmetic treatment of women's problems, which have increased women's marginalisation with the passage of time.

\section{Conclusion and Recomendations}

To sum up, different obstacles have been discussed which have affected the position of women and curtailed their choices about the productive and reproductive roles in the society. To understand women's subjugated peripheral position, in the society, WID and GAD have been discussed as analytical frameworks which provide some invaluable insights into the disempowerment of women sustained in patriarchal system. However, the major focus of WID approach is gender planning as tool of women's emancipation from the exploitative patriarchal system. Moreover, GAD finds connections and contradictions in gender; class and race and other differences. While using the position of women and social institutions and structures as analytical tool, GAD approach argues that there is no single factor that determines women's plight as women are affected by multiple variables such as race, class and ethnicity. Based on these assumptions, GAD approach argues that women's oppression varies from society to society, country to country and region to region. Therefore, there is no single variable, which could be accounted for in view of the worsening plight of women, and there is no single voice that could express all women's concerns. Hence, GAD can be considered as the most appropriate framework to be applied by policy makers and practitioner to understand women's low status in the society which is accentuated by rigid patriarchal structures, gender-blind state policies and gender discrimination, Elson (1995)

The gist of WID and GAD debate is that women, in some sections, who were invisible have now emerged as what Kabeer (1995) calls "important constituency" in the development. However, the existence of patriarchal beliefs and norms prevailing in Pakistani society has promoted a system where women find themselves subjugated over the years. Invariably, biased practices against women have deprived many women of their freedom of choice and independent decision making with regard to marriage, career and etc. Women's lack of access to resources has led to their weaker status and feeble bargaining power within and outside the household, making women more dependent on male and exploitation of such dependency at the hands of men is the order of the day in Pakistani society.

To improve women's status, and to enhance their bargaining position within the households, and more importantly for achieving their economic empowerment, following are the recommendations:

\begin{tabular}{l|llll}
\hline 96 & July 2012 & Volume 10 & Number 2 & JISR-MSSE
\end{tabular}


There is a greater need for gender sensitive development policies as suggested by proponents of GAD to address the primary and secondary needs of women, as the efficiency approach suggested by WID has totally failed to alleviate women poverty and their alienation due to antiwomen and anti-poor policies introduced under structural adjustment programmes by International Monetary Fund (IMF) since 1988.

For economic self-reliance and sustaining livelihood of women, the emphasis of the state or other agencies, which are primarily involved in women's welfare, should be on facilitating their access to credit, gainful employment, education and training as well as provision of much-needed social services while simultaneously reworking societal structures. The state should reduce gender inequality in education. Moreover, effective policies and plans to encourage female employment be implemented. There is a dire need to address perpetuated feminization of poverty through social security and protection measures and by asserting ownership such as land, property, and livestock (through inheritance, gift and joint title deeds).

\section{References}

Abdullah,T , "Feminization of poverty in Pakistan", lecture at The Institute of Strategic Studies, Islamabad on 12 January 2012.

Alavi, H 1991, "Pakistani women in a changing society" in Hastings Donna \& PininaWerber (eds.) Economy and Culture, Macmillan Press, London.

Azam, PA \& Gavino IB 2008, "Violence against women in Pakistan: A framework for analysis", Journal of Pakistan Medical Association, vol. 58, no.4, pp. 199-203.

Boserup, E 1970, Women's Role in Economic Development, St. Martin Press, New York.

Chowdhry, G 1995, "Engendering Development? Women in Development (WID)" in Marianne H. Marchand \& Jane Parpart (eds.) International Development Regimes, Feminism, Postmodernism and Development, Routledge, London.

Elson, D 1995, Rethinking Strategies for Development: From Male-biased to Human-centred Development, Manchester University Press, Manchester.

Felix, Q, "Honour Killing and 'Karo Kari' in Pakistan”, Available from: http://www.asian news.it/view. (27 July 2013).

Frances, S 1992, "Can Structural Adjustment Programs incorporate the interests of Women?" in Afshar \& Dennis (eds.) Women and Adjustment Policies in Third World, Macmillan, London.

Government of Pakistan, Economic Survey 2012-13, Finance Division, Islamabad.

Hali, SM 2013, “Women empowerment”, The Nation, 8 May.

Ibraz, T S \& Fatima A 1993, "Uneducated and unhealthy: the plight of women in Pakistan", The Pakistan Development Review, vol. 32, no. 4, pp. 905-915. 
Jeffery, P 1979, Frogs in a Well: Indian Women in Purdah, Zed Books, London.

Kabeer N 1995, Reversed Realities: Gender Hierarchies in Development, Verso, London. Kadir, MM, Fikree, FF, Khan A, \& Sajan, F 2003, "Do mothers-in-law matter? Family dynamics and fertility decision-making in urban squatter settlements of Karachi, Pakistan", Journal of Biosocial Science, vol. 35, issue 4, pp. 545-558.

Khan, EA \& Khan, T 2007, "Informally employed women: their characteristic and contribution in household budget', Journal of Applied Science, ISSN 1812-5654, vol. 7, no.14, pp.19011907.

Kumari, J 1986, Feminism and Nationalism in the Third World, Zed Books, London.

Molyneux, M 1989, Women in the Third World: Gender Issues in Rural and Urban Areas, Rutgers University Press, USA.

Mohanty, C 1997, "Under Western eyes: Feminist scholarship and colonial discourses", in Nalini Visvanathan et al. (eds.) The Women, Gender and Development Reader, Zed Books, London.

Moser, N 1993, Gender Planning and Development, Routledge, London.

Mumtaz, K 2007, “Gender and poverty in Pakistan”, Development, vol. 50, no. 2, pp. 149-153.

Niaz, U 2003, "Violence against women in South Asian countries", Arch Women's Mental Health, vol. 6 , no. 3, pp. 173-184.

Pardeep, P \& Bina, A 2005, "Marital violence, human development and women's property status in India", World Development, vol. 33, no. 5, pp. 823-850.

Ray, R 2000, "Poverty and expenditure pattern of household in Pakistan and South Asia: a comparative study", Journal of International Development, vol.12, no.2, pp. 241-56.

Saeed, Hilda 2013, "Poverty has a women's face", Dawn, 14 April, http://x.dawn.com/2013/04/14/poverty-has-a-womans-face/

Sathar, Z \& Kazi, S 2000, "Women's autonomy in the context of rural Pakistan", The Pakistan Development Review, vol. 39, no. 2, pp. 89-110.

Shaikh, MA 2003, "Is domestic violence endemic in Pakistan: perspective from Pakistani wives", Pakistan Journal of Medical Science, vol.19, no. 1, pp. 23-28.

UNDP (2010), http://hdr.undp.org/en/reports/regional/asiathepacific/RHDR-2010-AsiaPacific.pdf $(2 / 12 / 2012)$

UNDP (2011) Sustainability and Equity, Human Development Report 2011, United Nations Development Programme.

UNDP (2013) The rise of the South: Human Progress in a Diverse World, Human Development Report 2013, www.undp.org. Gilmore Printing Services Inc. Canada.

World Bank (1989) Women in Pakistan: An Economic and Social Strategy, World Bank(Report No. 8009-PAK) 1989, Country Study, Washington DC.

\begin{tabular}{l|llll}
\hline 98 & July 2012 & Volume 10 & Number 2 & JISR-MSSE
\end{tabular}


World Bank (1999) World Development Report 1996, 1997, 1999-2000.New York: Oxford University press.

World Bank (2002) Pakistan Poverty assessment, poverty in Pakistan: Vulnerabilities, Social Gaps and Rural Dynamics. Poverty reduction and Economic Management Sector Unit, South Asia Region Report No.24296- PAK.

Young, K 1997, "Gender and development", in Visvanathan N, Duggan L et al. (eds.) The Women, Gender and Development Reader, Zed Books, London. 